\title{
Outbreak of Salmonella enterica serotype Muenster INFECTIONS ASSOCIATED WITH GOAT'S CHEESE, FRANCE, MARCH 2008
}

\author{
D van Cauteren (d.vancauteren@invs.sante.fr) ${ }^{1,2}$, N Jourdan- da Silva1 ${ }^{1}$, F X Weill ${ }^{3}$, L King ${ }^{1}$, A Brisabois ${ }^{4}$, G Delmas ${ }^{1}$, V \\ Vaillant ${ }^{1}, \mathrm{H}$ de Valk $^{1}$ \\ 1. Institut de veille sanitaire, Saint-Maurice, France \\ 2. Programme de formation à l'épidémiologie de terrain (PROFET; Field Epidemiology Training Programme) \\ 3. Institut Pasteur, National Reference centre for Salmonella, Paris, France \\ 4. Agence Française de Sécurité Sanitaire des Aliments (French Food Safety Agency), Maisons-Alfort, France
}

\begin{abstract}
Salmonella enterica serotype Muenster (hereafter referred to as S. Muenster) is rare in France and in Europe. In France, a nationwide outbreak of gastrointestinal illness due to S. Muenster occurred during March and April 2008. Twenty-five laboratoryconfirmed cases of S. Muenster were documented by telephone using a trawling questionnaire. Four patients were admitted to hospital and no death was recorded. Among the 21 interviewed cases, 16 reported consumption of goat's cheese in the days prior to symptoms. The investigation incriminated goat's cheese from producer $X$ as being the most likely source of the outbreak. $\mathrm{S}$. Muenster was isolated from both cases and the incriminated goat's cheese. The pulsed-field gel electrophoresis profiles of the food isolates of producer $\mathrm{X}$ and the isolates from cases were indistinguishable. Following the withdrawal of the contaminated batch of cheese, the number of cases decreased to its usual level. To our knowledge, this is the first published outbreak of S. Muenster associated with food consumption in Europe.
\end{abstract}

\section{Introduction}

In France, the surveillance of Salmonella isolates of human and non-human origin is laboratory-based. The National Reference Centre (NRC) for Salmonella at the Institut Pasteur in Paris collects human isolates through a voluntary network of approximately 1,500 medical laboratories (corresponding to $30 \%$ of all French clinical laboratories). Animal, food and environmental isolates are collected by the French Food Safety Agency (Afssa) through a national voluntary network of 160 veterinary and food laboratories. Moreover, clusters of suspected food poisoning are subject to mandatory notification and must be reported to the relevant district health office (Direction départementale des affaires sanitaires et sociales, DDASS). An outbreak investigation is then conducted by the DDASS and veterinarians from the district veterinary service (Direction Départementale des Services Vétérinaires, DDSV), if necessary with the assistance of the French Institute of Public Health Surveillance (Institut de veille sanitaire, InVS).

Although salmonellosis is the largest documented cause of foodborne infections in France [1], Salmonella enterica serotype Muenster (hereafter referred to as S. Muenster) is rarely identified from humans, foods or animals. The NRC for Salmonella identified an annual average of 12 cases in the past three years. A total of $21 \mathrm{~S}$. Muenster isolates had been received by the Afssa between January 2006 and February 2008. Among them, four were food isolates (poultry); the other 17 strains were from different origins (meat and bone meal, environmental isolates). A documented food poisoning outbreak caused by S. Muenster occurred in Canada in 1982 and implicated cheddar cheese made from unpasteurised milk as the source of infection [2]. On 18 March 2008, the NRC for Salmonella reported three laboratory-confirmed cases of $S$. Muenster to the InVS. An investigation was conducted in order to confirm the outbreak, determine its extent, identify the source of infection and put in place control measures.

\section{Methods}

\section{Epidemiological information}

A case was defined as a person living in France with S. Muenster isolated from a stool or a blood specimen since 25 February of 2008 (week 9). Cases were reported by the NRC for Salmonella and clusters of cases were identified through the mandatory notification of suspected food poisoning. Basic epidemiological data (age, gender, district of residence, address of the medical laboratory) was available. Cases were interviewed by the relevant district health office or the InVS by telephone using a trawling questionnaire, in order to inquire about the onset of illness, type of symptoms, hospitalisation, and exposures during the week before the onset of illness such as contact(s) with other symptomatic individual(s), or with animal(s) or water, recent travel abroad, food consumption and the places where they had purchased food.

\section{European investigation}

The European Food- and Waterborne Diseases Network of the European Centre for Disease Prevention and Control (ECDC) was informed on 28 March of the ongoing outbreak in France, and the network members were requested to report any recent increase in number of cases of S. Muenster or any cases possibly linked to the French outbreak.

\section{Microbiological investigation}

Antimicrobial drug susceptibility was determined by disk diffusion as previously described [3]. Human and food isolates of 
S. Muenster linked to the outbreak as well as isolates not related to the outbreak (isolates received by the NRC in 2006 and 2007) were characterised by standard pulsed-field gel electrophoresis (PFGE) analysis of Xbal-digested chromosomal DNA [3]. Each profile that differed by at least one clear band $>100 \mathrm{~kb}$ was considered as a distinct profile. BioNumerics software (Applied Maths) was used to compare the PFGE profiles [4].

\section{Results}

\section{Epidemiological information}

Between 28 February and 24 April 2008, a total of 25 laboratoryconfirmed cases of S. Muenster were reported by the NRC to the

\section{F I G U R E 1}

Geographical distribution of S. enterica serotype Muenster infections according to Départment of residence, France, FebruaryApril 2008 ( $n=25$ identified cases)

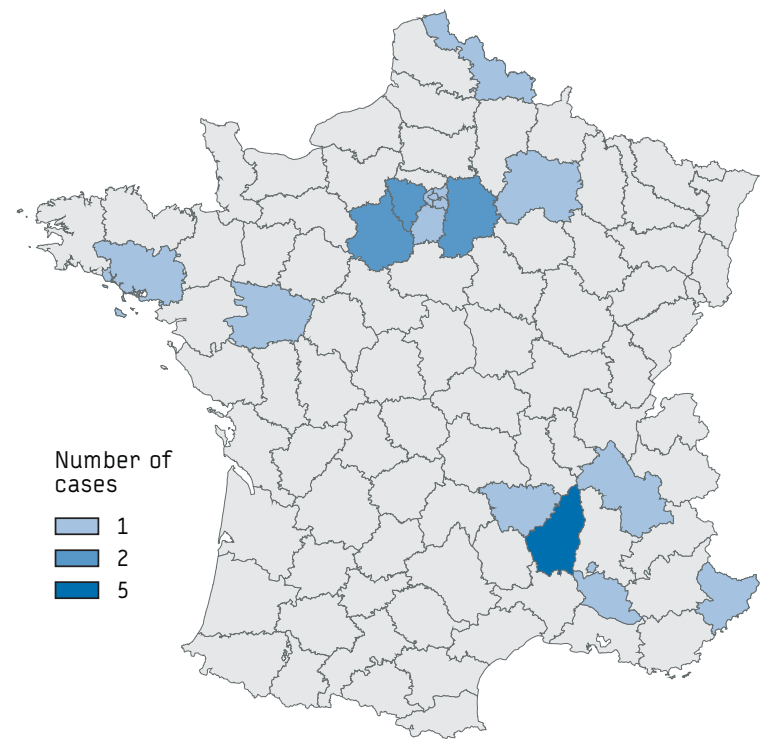

F I G U R E 2

Epidemic curve by week of onset of symptoms, S. enterica serotype Muenster, France, February-April $2008(n=20)$

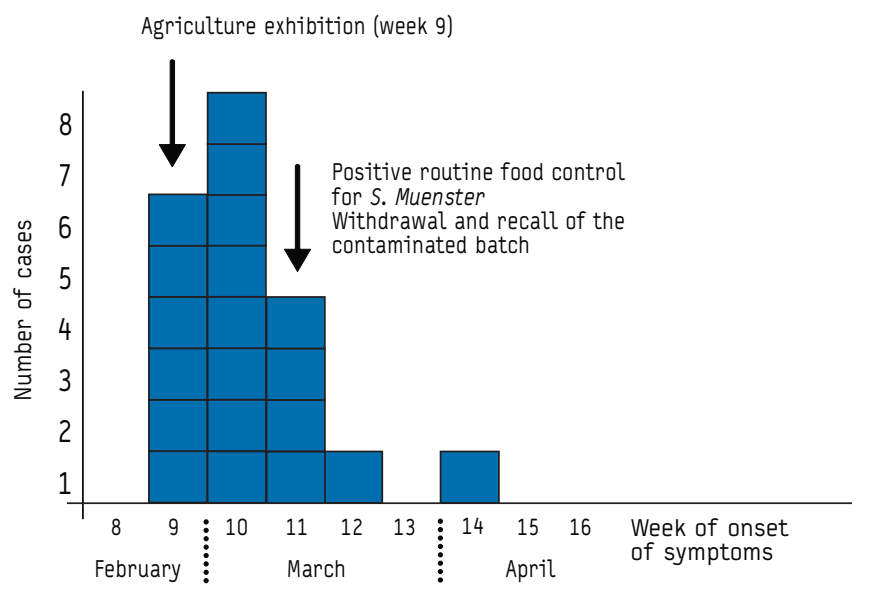

InVS, and among them six cases were reported as clusters of food poisoning through the mandatory notification. Four of them were isolated from children (8-12 years-old) and 21 from adults (median age 58 years). Only nine cases were male. The cases lived in 17 different administrative "Départments" spread across the country (Figure 1).

Of the 25 reported cases, 21 could be interviewed. The dates of onset of symptoms were from 27 February (week 9) to 3 April 2008 (week 14) (Figure 2). The most frequently reported symptoms were fever (20/21), diarrhoea (20/21), abdominal pain (17/21) and nausea (12/21). None of the interviewed cases had underlying medical conditions such as chronic illness or immunosuppressive therapy. Four patients were admitted to hospital and no death was recorded.

Among the 21 interviewed cases, 16 reported consumption of goat's cheese in the days before the onset of symptoms. The place of purchase of the goat's cheese was known for 10 cases: Seven cases had purchased unpasteurised goat's cheese at an agriculture exhibition that was held in Paris from 23 February until 2 March, and three cases had purchased this type of cheese at a local market in south-eastern France. Other food products frequently consumed were beef, ham, Emmentaler cheese and chicken (Table).

During the same period, a household cluster of salmonellosis involving three cases was reported through the mandatory notification system. The investigation of this cluster incriminated unpasteurised goat's cheese (consumed on 8 February 2008) as the source of infection. The isolates of these cases were later shown to be positive for S. Muenster.

In parallel, a routine food control was carried out on 14 March 2008 at a producer X, based in south-eastern France, and was positive for Salmonella for one of the batches of unpasteurised goat's cheese. This producer had delivered 360 unpasteurised goat's cheeses to the agriculture exhibition in Paris and supplied several local markets in south-eastern France. Control measures were taken by the producer immediately after this positive routine control: the contaminated batch and, as a precautionary measure, of all the other batches on the market were withdrawn and recalled. Following the withdrawal, the number of cases decreased to its usual level, around two isolates per month.

\section{European investigation}

A notification was made to the Rapid Alert System for Food and Feed (RASFF) on 20 March 2008 because the product had also been distributed to Belgium, Germany the Netherlands, and Sweden. No cases related to the French outbreak nor an unusual increase of S. Muenster isolates was reported from the ECDC's Food- and Waterborne Diseases Network.

\section{Microbiological investigation}

The human outbreak isolates of S. Muenster were susceptible to all antimicrobials tested. The PFGE profile (XMUENS-11) of the 20 isolates related to the outbreak was identical to the one of the food isolates of producer $X$. Ten different profiles other than XMUENS-11 were observed for the 12 isolates found in 2006 and 2007 from cases not related to the outbreak (Figure 3). 


\section{Discussion}

We describe a nationwide salmonellosis outbreak involving 25 cases of infection with the uncommon serotype Muenster that occurred in France between February and April 2008. The investigation incriminated unpasteurised goat's cheese from producer $\mathrm{X}$ as being the most likely source of the outbreak.

The incrimination of this goat's cheese was supported by the following findings: Firstly, a high proportion of cases (16 of 21) reported having eaten goat's cheese from the same small producer $X$. Secondly, a cluster of cases followed the consumption of goat's cheese from producer $X$. Thirdly, there was a concordance between the temporal (March 2008) and the geographical occurrence (agriculture exhibition in Paris and the south-eastern France) for the majority of the cases, and the distribution of goat's cheese of the producer X. Moreover, S. Muenster is a rare Salmonella serotype that was isolated from both cases and the incriminated goat cheese. The PFGE profiles of the food isolates of producer $X$ and the isolates from the cases were identical. All isolates from related cases had an indistinguishable PFGE profile not previously identified. It was decided not to carry out an analytical study because of the findings discussed above.

T A B L E

Food exposures of interviewed cases of $S$. enterica serotype Muenster, France, February-April 2008 (n=21)

\begin{tabular}{|l|l|}
\hline \multicolumn{1}{|c|}{ Food exposure } & \multicolumn{1}{c|}{ Number/total } \\
\hline Goat's cheese & $16 / 21$ \\
\hline Beef & $11 / 21$ \\
\hline Ham & $10 / 21$ \\
\hline Emmentaler cheese & $9 / 21$ \\
\hline Chicken & $9 / 21$ \\
\hline
\end{tabular}

\section{F I G U R E 3}

Pulsed-field gel electrophoresis profiles of XbaI-digested DNA from S. enterica serotype Muenster isolates, France

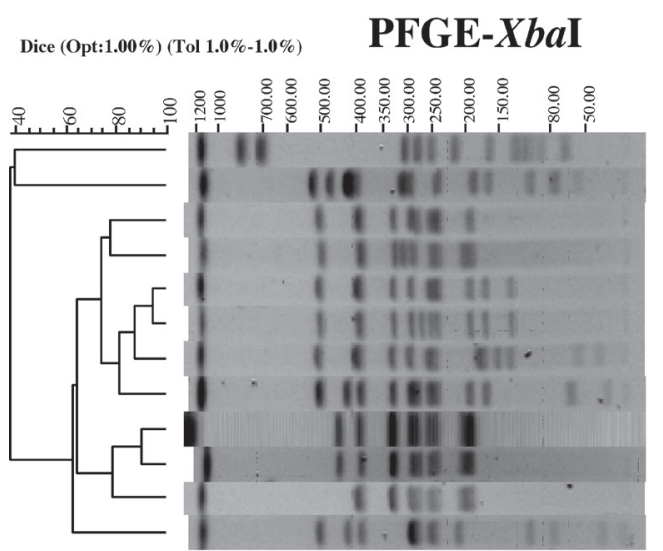

Profil

XMUENS-2

XMUENS-10

XMUENS-4

XMUENS-6

XMUENS-3

XMUENS-7

XMUENS-5

XMUENS-8

SMUEXB0007

XMUENS-11

XMUENS-1

XMUENS-9

XMUENS-11: isolate from a case in this outbreak;

SMUEXB0007: food isolate of producer $X$;

XMUENS-2-10: isolates from patients identified in France in 2006 and 2007 that were not associated with this outbreak.

Source: French National Reference Centre for Salmonella and French Food

Safety Agency.
This event was picked up by three surveillance systems. The NRC for Salmonella and the mandatory notification of clusters of food poisoning performed well by reporting cases of S. Muenster simultaneously to the InVS. The positive routine food control of producer $\mathrm{X}$ allowed early withdrawal of the contaminated batch, resulting in a limited number of cases.

In the literature, unpasteurised dairy products have been shown to cause outbreaks of salmonellosis, campylobacteriosis, listeriosis and Shigatoxin-producing Escherichia coli (STEC) infections, including cases of haemolytic-uraemic syndrome. In spite of the large amounts of many different types of raw milk cheeses consumed in France, foodborne outbreaks related to these cheeses remain relatively rare [5-8]. To our knowledge, this is the first published outbreak of S. Muenster associated with food consumption in Europe. This outbreak highlighted also the importance of routine food controls in order to prevent communitywide outbreaks of salmonellosis and other foodborne infections.

\section{Acknowledgements}

We would like to thank the members of the Direction départementale des affaires sanitaires et sociales of Ardèche (dep 07) and Eure et Loire (dep 28).

\section{References}

1. Vaillant V, de Valk H, Baron E, Ancelle T, Colin P, Delmas MC, et al. Foodborne infections in France. Foodborne Pathog Dis. 2005;2(3):221-32.

2. Wood DS, Collins-Thompson DL, Irvine DM, Myhr AN. Source and persistence of Salmonella muenster in naturally contaminated Cheddar cheese. J Food Prot,1984;47(1):20-2.

3. Weill FX, Demartin M, Tandé D, Espié E, Rakotoarivony I, Grimont PA. SHV-12-like extended-spectrum-beta-lactamase-producing strains of Salmonella enterica serotypes Babelsberg and Enteritidis isolated in France among infants adopted from Mali. J Clin Microbiol. 2004:42(6):2432-7.

4. Ribot EM, Fair MA, Gautom R, Cameron DN, Hunter SB, Swaminathan B, et al. Standardization of pulsed-field gel electrophoresis protocols for the subtyping of Escherichia coli 0157:H7, Salmonella, and Shigella for PulseNet. Foodborne Pathog Dis. 2006;3(1):59-67.

5. Desenclos JC, Bouvet $P$, Benz-Lemoine E, Grimont F, Desqueyroux H, Rebièr I, et al. Large outbreak of Salmonella enterica serotype paratyphi B infection caused by a goats' milk cheese, France, 1993: a case finding and epidemiological study.BMJ.1996;312(7023):91-4.

6. Dominguez M, Jourdan-Da Silva N, Vaillant V, Pihier N, Kermin C, Weill FX, et al. Outbreak of Salmonella enterica Serotype Montevideo Infections in France Linked to Consumption of Cheese Made from Raw Milk. Foodborne Pathog Dis. 2009;6(1):121-8.

7. Espié E, Vaillant V.International outbreak of Salmonella Stourbridge infection, April- July 2005: results of epidemiological, food and veterinary investigations in France. Euro Surveill. 2005;10(32):pij=2772. Available from: http://www.eurosurveillance.org/ViewArticle.aspx? ArticleId $=2772$

8. De Buyser ML, Brisabois A, Espié E, Delmas G, Dufour B. Implication du lait et des produits laitiers dans les maladies infectieuses d'origine alimentaire en France de 1988 à 2003. [Implication of milk products in infectious diseases of food origine in France from 1988 to 2003]. Bulletin Epidemiologique - Afssa. 2005;16:1-2. [In French]. Available from: http://fulltext.bdsp.ehesp.fr/Afssa/ BulletinAfssa/2005/16/1.pdf?80XMK-M3G81-X4KK3-480XG-KJ314

This article was published on 6 August 2009.

Citation style for this article: van Cauteren D, Jourdan-da Silva N, Weill FX, King L, Brisabois A, Delmas G, Vaillant V, de Valk H. Outbreak of Salmonella enterica serotype Muenster infections associated with goat's cheese, France, March 2008. Euro Surveill. 2009;14(31):pii=19290. Available online: http://www.eurosurveillance.org/ViewArticle. aspx?ArticleId $=19290$ 